ISSN: 2162-3104 Print/ ISSN: 2166-3750 Online

Volume 8, Issue 1 (2018), pp. 194-214

(C) Journal of International Students

http://jistudents.org/

doi: 10.5281/zenodo.1134289

\title{
Academic Adaptation Among International Students from East Asian Countries: A Consensual Qualitative Research
}

\author{
Jiaqi Li \\ Wichita State University, United States \\ Yanlin Wang \\ Texas Tech University, United States \\ Xun Liu \\ Virginia Commonwealth University, United States \\ Yusu Xu \\ Zhejiang Gongshang University, China \\ Tingting Cui \\ Jilin University, China
}

\begin{abstract}
This study used a consensual qualitative research method to explore academic adaptation experiences of international students $(N=13)$ from East Asia countries at a U.S. university. The analysis yielded five domains from the data (challenges, feelings, strategies, suggestions, and selfreflections). Implications for college counselors, university administrators, and future research are discussed.
\end{abstract}

Keywords: academic adaptation, consensual qualitative research, East Asian international students 
The number of East Asian international students in the United States is rapidly increasing (Li, Marbley, Bradley, \& Lan, 2016; Li, Wang, \& Xiao, 2014). In the 2014-2015 academic year, there were 975,926 international students studying at U.S. colleges and universities, with a continued growth rate of $10 \%$ over the past decades (Institute of International Education, 2016). Of the top countries of origin of international students, $42 \%$ come from East Asia: China, South Korea, Japan, and Taiwan (Institute of International Education, 2016). According to the National Association for Foreign Student Affairs (NAFSA, 2015), international students provide huge economic benefits (\$30.5 billion, 2014/2015) and enhance academic institutions in the United States in terms of diversifying the campus. However, research has indicated that international students, especially from East Asian countries have a series of cross-cultural difficulties related to adapting into American higher education systems (Baba \& Hosoda, 2014; Hamamura \& Laird, 2014; Li, Liu, Wei, \& Lan, 2013; Zhou, Frey, \& Bang, 2011). Moreover, there has been limited research conducted on the experiences associated with academic adaptation among East Asian international students (Zhou et al., 2011). Therefore, college counselors, university administrators, and researchers need a better understanding of the issues that East Asian international students face in their sojourner experiences.

\section{LITERATURE REVIEW}

\section{East Asian International Students}

Students from Asian countries are often classified as Asian international students at U.S. colleges and universities. However, there are significant differences among these students in terms of their culture, religion, ethnicity, and language (Holt, 2015). This study focuses on a group of international students originally from East Asia, including China, Japan, and South Korea. By geographical location, these students are defined as East Asian international students so as to differentiate them from students from other Asian countries such as India or Vietnam. As far as the purpose of research is concerned, East Asian international students account for a high percentage of international students studying in the United States (Roy, 2013), hold similar cultural and ethnic characteristics that "stem from a complex history of race relations" (Ritter, 2015, p. 405), and have a strong motivation for academic achievement (Kondo-Brown, 2009; Yu \& Downing, 2011). 


\section{Academic Adaptation Challenges}

Existing research on East Asian international students has identified a number of variables that play a vital role in academic adaptation. These variables include, but are not limited to, English language proficiency and classroom learning styles (Leong, 2015; Li et al., 2016; Yeh \& Inose, 2003; Zhou et al., 2011). For instance, numerous studies have indicated the influence of English language proficiency on academic achievement and social adaptation among international students, particularly for East Asian students studying in U.S. universities and colleges (Light, Xu, \& Mossop, 1987; Liu, 2001; Spinks \& Ho, 1984; Zhou et al., 2011). In an investigation of 979 international students, Rosenthal, Russell, and Thomson (2008) found that $24 \%$ of Asian students report having difficulties in written English and $22 \%$ in spoken English, along with a high level of psychological distress. Similarly, Yeh and Inose (2003) investigated the effect of reported English fluency on acculturative stress among a sample of 359 international students in the context of Europe and Asia. Their findings indicated that a high level of English language fluency can improves academic performance amongst Asian international students. Likewise, Leong (2015) qualitatively examined the academic experiences of 11 international students (seven of them are from China). In Leong's findings, English language proficiency was considered as the primary challenge and barrier to students' academic success.

Most Asian international students whose first language is not English have to encounter more complexities and challenges than domestic students when they take university courses (Yan \& Berliner, 2013; Spinks \& Ho, 1984; Zhou et al., 2011). The learning style in U.S. classrooms are different from what Asian students are used to in their home countries (Wong, 2004). More specifically, Asian students employ different learning approaches (e.g., traditional lecture format) from their American classmates. East Asian students focus on memorization with the purpose of obtaining satisfied grades and passing exams (Leder \& Forgasz, 2004; Samuelowicz, 1987). These students are sometimes labelled as surface or passive learners by Western society (Biggs, 1996; Watkins, 1996). When East Asian international students arrive in the United States, they experience a structured education system that brings them much greater freedom in course choice and personal time management than their home universities. Meanwhile, studying at U.S. universities also requires Asian students to adapt into a culturally and linguistically different study environment, which emphasizes critical thinking, creativity, and initiative (McClure, 2003). 


\section{Conceptual Framework}

The conceptual framework for the current study was informed by Berry's $(1997,2005)$ acculturation model as well as consensual analysis of literature discussed by Hill (2010). Specifically, Berry (1997) proposed a multidimensional theory of acculturation, including four possible strategies of acculturation such as assimilation, separation, integration, and marginalization. This model provides a comprehensive framework that can be used as a conceptual lens to make sense of how individuals are able to function in ethnic and dominant cultures. In addition, we reviewed Zhou et al.'s (2011) findings in order to provide a picture of where we began our research on academic adaptation. To respond to Zhou et al.'s call for exploring identified subthemes through a specific sample, the present study examines the academic experiences of a group of East Asian international students at a deeper level using a consensual qualitative research (CQR) method. Together, these factors were deemed an ideal lens for the current study.

\section{RESEARCH METHOD}

Given the exploratory nature of this study, we chose to use a consensual qualitative research (CQR) method (Hill, 2010; Hill et al., 2005). Compared to other forms of qualitative research, Hill (2010) stated that this methodology is "ideal for studying in depth the inner experiences, attitudes, and beliefs of individuals because it allows researchers to gain a rich, detailed understanding" (p. 15). The purpose of this study was to fill the gap in the literature by developing a deep understanding of meaningfully academic adaptation of East Asian international students in the United States. Accordingly, we developed five specific research areas through a team of researchers' consensual agreement and from a review of the literature (Li et al., 2016; Liu, 2001; Poyrazli et al., 2004; Zhou et al., 2011): (a) challenges, (b) feelings, (c) strategies, (d) suggestions, and (e) selfreflections.

\section{Participants}

Hill (2010) recommended that the ideal sample size of $\mathrm{CQR}$ is between 12 and 15 which are sufficient to find some consistency in the results. By applying this rule, a total of 13 East Asian international students enrolled at a large-sized public university located in the Midwestern United 
States participated in the current study. Participants also met the following criteria: (a) They were students originally from East Asian countries (China, Japan, North Korea, South Korea, Mongolia, or Taiwan); and (b) their average time spent in the United States was between 1 and 6 years. Using this range, participants were able to reflect on their feelings and experiences while they moved to a culturally diverse campus. There was not any reward or compensation for all participants.

Of 13 participants, seven $(53.8 \%)$ were from China, two $(15.4 \%)$ were from Taiwan, three $(23.1 \%)$ were from South Korea, and one $(7.7 \%)$ was from Japan. All participants identified as Asian, with eight out of the participants identifying as male $(61.5 \%)$ and five identifying as female (38.5\%). Participant ages ranged from 19 to 40 years old $(M=23.69, S D=$ 5.57), and their length of stay in the United States ranged from 1 to 6 years $(M=3.19, S D=1.56)$. In regard to the academic degree, there were nine undergraduates $(69.2 \%)$, two master's students $(15.4 \%)$, and two doctoral students $(15.4 \%)$.

\section{Procedure}

Participants were recruited through student associations at the university after receiving institutional review board approval. The investigators contacted the associations' chairs regarding the appropriate protocol for sending invitation letters to potential participants. The sample of participants was selected based on meeting the selection criteria and with the intention to include participants from various countries to yield diverse perspectives with regards to their academic adaptation experiences. Once participants were identified, we emailed them a research packet that included the informed consent, a demographic questionnaire, and a copy of the interview questions. After we received signed informed consent forms, we scheduled either face-to-face or telephone interviews using semistructured interview questions as a guide. For the face-to-face and telephone interviews, dialogues were audio recorded and then transcribed for the further analysis. All interviews lasted approximately $40 \mathrm{~min}$. At the end of the interviews, participants were given an opportunity to review their responses for clarifications or omissions, and participants were assured that their names or identifying information were not included in the data report. Interview questions were developed based on the literature and focused on five research areas of interest: Question 1-3 asked about academic challenges (e.g., "what academic challenges have you experienced?"); Questions 4-5 were related to feelings (e.g., "what were the feelings 
associated with difficulties you have?"); Questions 6-7 focused on strategies (e.g., "what was your strategy in overcoming the difficulties?"); Questions 8-9 invited participants to give suggestions to their fellow students (e.g., "what suggestions would you like to give to your fellow students?"), and Question 10 was a self-reflection question (e.g., "what did you learn about yourself from answering these questions?").

\section{Data Analysis}

The CQR data analysis, as outlined by Hill (2010), in our study consisted of two major steps (within-case analysis and cross-analysis) as well as seven minor ones (develop domains, construct core ideas, auditors check, revise domains/core ideas, develop categories within domains across all cases, auditors check cross-analysis, and revise cross-analysis based on audit). In the step of within-case analysis, three researchers independently viewed the final verified transcripts to develop a list of domains and core ideas. Upon completion, researchers met to consensually create a finalized domain/core idea list that best fit the focus of the study. When disagreements during any part of the analysis came up, researchers went back to the raw data in order to reach a consensus. Once the domains and core ideas were identified, the auditor reviewed the consensus to ensure that the data were accurately presented. During the process, the domains and core ideas were repeatedly revised and "debated" among the research team members until the domain/core idea list was finalized. In the step of crossanalysis, researchers constructed a consensus version of the categories (domains/core ideas) as an outline for each case. Then data (core ideas) from each case were placed into each category. Hill et al. (1997) and Hill (2010) suggested that three levels (general, typical, and variant) of frequency of occurrence of the categories can be used in a CQR cross-analysis. The frequency labels in the current study were shown as general (e.g., English proficiency, course readiness), typical (e.g., connecting with locals, positive feelings), and variant (e.g., time management, dependence). Similar to the step of within-case analysis, researchers carefully examined each category to ensure that the data were accurate and fully presented. Then the auditor reviewed the cross-analysis and provided detailed feedback regarding data consistency and accuracy for the research team members. This process was continually repeated before the revision was finalized by team consensus. 


\section{Research Team}

The research team consisted of two assistant professors, one postdoctoral fellow, and one visiting scholar. All research team members were trained in CQR (e.g., reading CQR books, reviewing CQR articles) and shared similar research interests. The first author was the principal investigator and served as an auditor in this study. The rest of the members participated in recruiting, interviewing, transcribing, and coding.

\section{Trustworthiness}

As recommended by Hill (2010) and Hill et al. (2005), we used several methods to establish trustworthiness and reduce researcher bias. Firstly, all research team members discussed their expectations and biases that might have influence on their interviewing and coding at the beginning of the study. Reporting expectations and biases allowed researchers to identify their own perceptions and interpretations of the data in the analysis. Secondly, we piloted the interview protocol with two people who met the participation criteria, but were not participating in the formal study. These pilot interviews allowed researchers to examine if interview questions functioned properly and logically. During the pilot interview, we revised several questions and adjusted the sequence of asking questions. Lastly, member checking was also involved in our study to ensure the accuracy and trustworthiness of the data (Hill et al., 2005). Upon the completion of transcription, we sent them to the participants to check for accuracy.

\section{RESULTS}

As shown in Table 1, our within-case analysis yielded five domains (challenges, feelings, strategies, suggestions, and self-reflections), 16 core ideas (e.g., English proficiency, positive feelings), and 24 subcore ideas (e.g., improve English, know rules and set boundaries) that emerged from the data. Likewise, cross-analysis revealed that four categories (e.g., English proficiency, course readiness) were labeled as "general" (having 12 to 13 responses), five categories (e.g., connecting with locals, positive feelings) were labeled as "typical" (seven to 11 responses), and seven categories (e.g., time management, isolation) were labeled as "variant" (two to six responses). These domains, as well as core and subcore ideas, are discussed in the following paragraphs. Pseudonyms are used to maintain the confidentiality of each participant. 
Table 1. Summary of domains, core ideas, frequency, respondents, and subcore ideas.

\begin{tabular}{|c|c|c|c|c|}
\hline Domains & Core ideas & Frequency & Respondents & Subcore ideas \\
\hline \multirow[t]{8}{*}{ Challenges } & $\begin{array}{c}\text { English } \\
\text { Proficiency }\end{array}$ & General & 12 & Improve English \\
\hline & & & & $\begin{array}{l}\text { Afraid to speak } \\
\text { English }\end{array}$ \\
\hline & $\begin{array}{l}\text { Connecting } \\
\text { with locals }\end{array}$ & Typical & 8 & $\begin{array}{l}\text { Learn to cope with } \\
\text { classmates/professors }\end{array}$ \\
\hline & & & & $\begin{array}{l}\text { Know rules and set } \\
\text { boundaries }\end{array}$ \\
\hline & $\begin{array}{l}\text { Course } \\
\text { readiness }\end{array}$ & General & 13 & $\begin{array}{l}\text { Adapt to professor's } \\
\text { teaching style }\end{array}$ \\
\hline & & & & Adjust study loads \\
\hline & & & & Select course wisely \\
\hline & $\begin{array}{l}\text { Time } \\
\text { management }\end{array}$ & Variant & 3 & $\begin{array}{l}\text { Improve time } \\
\text { management skills }\end{array}$ \\
\hline \multirow[t]{2}{*}{ Feelings } & $\begin{array}{l}\text { Negative } \\
\text { feelings }\end{array}$ & General & 12 & $\begin{array}{l}\text { Frustrate, overwhelm, } \\
\text { stressful, exhausted, } \\
\text { powerless }\end{array}$ \\
\hline & $\begin{array}{l}\text { Positive } \\
\text { feelings }\end{array}$ & Typical & 7 & $\begin{array}{l}\text { Funny, positive, \& } \\
\text { determined }\end{array}$ \\
\hline \multirow[t]{9}{*}{ Strategies } & Self-reliance & General & 12 & Set up specific goals \\
\hline & & & & Take notes \\
\hline & & & & $\begin{array}{l}\text { Use an appointment } \\
\text { book }\end{array}$ \\
\hline & & & & $\begin{array}{l}\text { Find the right place to } \\
\text { study }\end{array}$ \\
\hline & Dependence & Typical & 8 & $\begin{array}{l}\text { Utilize campus } \\
\text { resources }\end{array}$ \\
\hline & & & & $\begin{array}{l}\text { Participate in study } \\
\text { groups }\end{array}$ \\
\hline & & & & $\begin{array}{l}\text { Ask study tips from a } \\
\text { senior fellow }\end{array}$ \\
\hline & Isolation & Variant & 2 & Home bird \\
\hline & Integration & Variant & 3 & $\begin{array}{l}\text { Learn actively and ask } \\
\text { for helps often }\end{array}$ \\
\hline
\end{tabular}




\begin{tabular}{|c|c|c|c|c|}
\hline Domains & Core ideas & Frequency & Respondents & Subcore ideas \\
\hline \multirow[t]{5}{*}{ Suggestions } & Self-reliance & Typical & 11 & Set up specific goals \\
\hline & & & & Improve English \\
\hline & & & & $\begin{array}{l}\text { Learn to balance study } \\
\text { and life }\end{array}$ \\
\hline & Dependence & Variant & 5 & $\begin{array}{l}\text { Ask study tips from a } \\
\text { senior fellow }\end{array}$ \\
\hline & & & & $\begin{array}{l}\text { Participate in study } \\
\text { groups }\end{array}$ \\
\hline \multirow[t]{4}{*}{$\begin{array}{l}\text { Self- } \\
\text { reflections }\end{array}$} & $\begin{array}{l}\text { Improve self- } \\
\text { esteem }\end{array}$ & Variant & 3 & $\begin{array}{l}\text { Know my strength } \\
\text { and ability, self-affirm }\end{array}$ \\
\hline & $\begin{array}{l}\text { Be very busy } \\
\text { studying }\end{array}$ & Typical & 7 & $\begin{array}{l}\text { Spend twice as long } \\
\text { on doing assignments }\end{array}$ \\
\hline & $\begin{array}{l}\text { Have a } \\
\text { wonderful } \\
\text { memory of } \\
\text { studying } \\
\text { abroad }\end{array}$ & Variant & 3 & $\begin{array}{l}\text { Wonderful experience } \\
\text { on campus }\end{array}$ \\
\hline & $\begin{array}{l}\text { Always make } \\
\text { positive } \\
\text { changes }\end{array}$ & Variant & 3 & $\begin{array}{l}\text { A new sense of } \\
\text { autonomy, always } \\
\text { make a choice }\end{array}$ \\
\hline
\end{tabular}

Note. General is for 12 to 13 responses; typical is for 7 to 11 responses; variant is for 2 to 6 responses.

\section{Challenges Domain}

The first domain was identified as challenges. Each participant made comments on the challenges they faced during their study in the United States. As one of the largest categories in our study, the Challenges domain includes four core ideas: (a) English proficiency, (b) connecting with locals, (c) course readiness, and (d) time management.

\section{English Proficiency}

Nearly all participants described concerns about their English language proficiency as well as expectations to improve their English. Furthermore, they considered English proficiency to be the most challenging part of their study. For example, John, one of students from China, expressed his difficulty in following what the professor spoke of in lectures 
stating, "there are a lot of vocabularies I do not know, so I have to look up them on my dictionary and it takes me very long time. After I understand the words, I have missed his (professor) PPT slides." Another student from South Korea, Cho, mentioned that it took him several months adapting to class. As Cho explained, "they [professor and American students] talk too fast and have strong accent; it is very difficult for me to understand what they are talking about." Other participants reported similar concerns in their English language skills, especially in communication with other students and professors and with writing an academic paper. This core idea is consistent with some other findings related to English proficiency among Asian international students (Li et al., 2016; Li et al., 2014; Mak, Bodycott, \& Ramburuth, 2015).

\section{Connecting with Locals}

This core idea entailed interaction with faculty, staff, and students through different methods of communication such as face-to-face, emails, texts, and phone calls. The majority of participants reported that they felt disconnected from their professors and classmates. For example, Emma, a master's student from China, shared, "I barely talk to my advisor. I have no idea what other professors and students are doing. No idea how to approach them." Another student, Peter, a PhD student from Taiwan, expressed his concerns about networking by stating that, "I want to know what research other professors and students are doing in the department, and do not know how to speak to them. I realize that I need my advisor and other professors to recommend some job opportunities for me. But I did not build a good relationship with them in the past. So I am afraid that I will not get strong recommendations from my professors when I seek jobs. It makes me very frustrated now."

\section{Course Readiness}

All participants shared how being immersed in an academic culture that was different from their own influenced their course readiness and awareness of their own cultural norms. In our study, participants focused on three major course challenges that they have personally experienced: (a) adapting to a professor's teaching style (e.g., PowerPoint, syllabus), (b) selecting courses wisely (e.g., online, face-to-face, or hybrid), and (c) adjusting study loads (e.g., 9 to 18 credit hours). For example, Han, an undergraduate student from China, said, "the department helps decide what 
courses I need to take as a freshman while I am in China. Here I have to select the course by myself. Although I have an advisor to give me some suggestion, I think that it does not help me too much. It is a little bit challenging for me. I am not ready for this."

\section{Time Management}

Three out of 13 participants made comments related to time management during their study. A common perception among students is that they are always short on time. Tina, a Japanese student, remarked, "there are so much going on at our university campus. I feel overcommitted and need to prioritize my time. My schedule is very tight because I am taking on too much."

\section{Feelings Domain}

The second domain identified was Feelings. This represented a categorization of expressed feelings associated with academic adaptation. Coders came to consensus on two core ideas that consisted of positive and negative feelings within the content of this session. Further, a total of five subcore ideas emerged related to negative feelings (frustration, overwhelming, stress, exhaustion, and powerlessness) as well as positive feelings (fun, positiveness, and determination). Surprisingly, nearly all participants reported negative feelings which they had experienced during their study. For example, Han stated,

"I am super busy in my freshman year. I have to take care of my stuff such as selecting dorm, finding appropriate roommates, selecting courses, and buying texts. It's overwhelming and very stressful! Nobody helps me. I do not know where to find helps. Sometimes, I really want to go back to my country so I do not need to handle so many things. Studying here might be a wrong choice. I feel frustrated because I am unable to keep up with my class. But I do not go back home because I promise my parents that I will obtain a degree here. I must not lose their faces. I am exhausted." 


\section{Strategies Domain}

For the purpose of this study, strategies are defined as the plan of action East Asian international students used to cope with their academic challenges. Given the sources of help and advice students seek, coders agreed that strategies consisted of self-reliance (12 responses), dependence (eight responses), and isolation (two response), namely depending on self, asking help from others, or relying on neither self nor others. Interestingly, 12 participants reported that they were inclined to depend on themselves (e.g., manage time effectively, study hard) while two considered themselves as being isolated (e.g., "I don't care about my scores! I just want to get my degree and go back to my country so I do not necessarily study as hard as others," "I am a home bird. I enjoy watching movies and playing video games in my apartment after the class."). Furthermore, eight participants discussed the importance of seeking help and advice from others (e.g., participate in study teams, utilize campus resources). Chris, a student from South Korea, noted, "American class put a high emphasis on teamwork. I learn a lot from teamwork with my American classmates and professors." Another student, Emma, discussed campus resources, stating, "there are many free resources you can utilize on campus such as counseling, recreation, career, and writing center. I like going to writing center to revise my paper, career center to do career interest test, and recreation center for workout."

\section{Suggestions Domain}

The Suggestions domain emerged based on suggestions participants gave to their fellow students. Coders came to consensus on suggestions which included two types of options (self-reliance and dependence strategy) that participants gave related to sources of help and advice on campus. Three subcores were found within the self-reliance strategy while two were from the dependence strategy. Consistent with findings in the Strategies domain, a majority of participants suggested that fellow students should depend on themselves (self-reliance strategy) through the following methods: (a) set up specific goals, (b) improve English, and (c) learn to balance study and life. Likewise, the dependence strategy suggestion included: (a) ask for study tips from a senior fellow and (b) utilize campus resources. Alan, a doctoral student from Taiwan, gave his suggestions as follows: 
"I saw many Asian students transfer from other majors to Electric Engineering. They often struggle in this program because they do not know how to study and their English is not good. If I were them, I will improve my English first and ask my professors and classmates on how to survive and excel myself in this department. They [Asian students] sometimes are just too shy to ask questions or simply unwilling to do that. They really need to often seek help from their professors instead of asking their friends from the same country. It's sometimes useless."

\section{Self-Reflections Domain}

In the last domain, participants in our study reflected on a wide array of experiences and feelings that occurred during their study. Core ideas within this domain included: (a) improve self-esteem; (b) being very busy studying; (c) having a wonderful memory of studying abroad; and (d) making positive changes. Importantly, three participants reported they want to improve self-esteem because they suffered from language discrimination on campus. For example, Eason (Chinese graduate) stated,

"Sometimes I was reluctant to buy a sandwich on campus because I did not know the type of bread/veggies/cheese and have no idea what to pick. Also, they (sellers) seem not understanding my English and look very impatient while I tried to order. Those people (professors/classmates) often look impatient and down on me because of my accent and syntax. I also feel that my American classmates do not want to make presentations with me because of my English. When I was in a team with them, they discussed and decided what they like to do and gave me the part they were not interested in. It is not respectful to me. It is a discrimination!"

\section{DISCUSSION}

This study was designed to gain a deeper understanding of academic adaptation among East Asian international students in the United States. Based on previous findings (Bista, 2015; Li et al., 2014; Zhou et al., 2011), our analysis of interviews of 13 participants highlighted five domains related to academic challenges, feelings, strategies, suggestions, and selfreflections. Examining these domains, core ideas, and subcores not only revealed several themes consistent with previous research (Li et al., 2016; Mak et al., 2015; Johnson, 1988; Zhou et al., 2011), it also addressed 
primary research questions as follows: "what academic challenges have East Asian students experienced in the United States? How would these students face these challenges?" Finally, the limitations of the study, implications for college counselors, and future research are discussed in the next section.

\section{Challenges and Feelings}

Some findings of the challenges domain are compatible with previous research on English proficiency (Li et al., 2014; Mak et al., 2015; Martirosyan, Hwang, \& Wanjohi, 2015) and course readiness (Zhou et al., 2011). As Martirosyan et al.'s (2015) study found, English language proficiency has an impact on the academic performance of international students. Other researchers have also stated there is a statistically significant relationship between English proficiency and academic adaptation among Asian international students (Johnson, 1988; Li, Chen, \& Duanmu, 2010). Moreover, we discovered there is a strong language learning motivation emerging from our interviews. From East Asian international students' perspectives, we observed that a majority of the participants (from undergrads to doctoral students) realized the importance of enhancing their language skills and were engaged in a variety of activities related to English improvement. Zhou et al.'s (2011) study pointed out high learning motivations and positive learning attitudes from international graduate students. Our results, thus, build on Zhou et al.'s findings and provide evidence in a different context. On the other hand, our study demonstrates inevitable issues involving students' course readiness. Culturally and linguistically different teaching styles, curriculum structure, and the minimum credit hour requirements for international students were impacting these student participants, and could be contributing factors associated with academic adaptive stress. These findings also support Misra, Crist, and Burant's (2003) earlier research that international students' academic stress is associated with coursework and responsibilities.

The feelings that these students described in their interviews were associated with academic stress from heavy course load, academic competence, and high expectations. This is in line with Liao and Wei's (2014) finding that academic stress impacts international students' psychosocial adjustment to life in the United States. In addition, these findings reflect Berry's (1997) theoretical model on acculturative stress, which indicates that characteristics of individual (e.g., East Asian values) influence acculturation experience (e.g., psychological well-being of individuals) in a culturally diverse society. Moreover, participants used 
many negative terms (e.g., frustrated, stressful) to describe their feelings when asked about their experiences during their study. Similarly, Li et al.'s (2013) findings concluded that Chinese international students suffered a high level of stress and depression in the acculturation process.

\section{Strategies, Suggestions, and Self-Reflections}

The following domains identified by this study include the strategies that students used in relation to academic adaptation. In reference to Berry's (1997, 2005) acculturation strategies, they used self-reliance strategies (attitudes and behaviors for seeking help from themselves), dependence strategies (from others), integration strategies (from both) and isolation strategies (neither depend on themselves nor seek help from others). In our study, participants showed a great tendency to depend on themselves for coping with issues related to academic adaptation. Accordingly, their attitudes and behaviors of help-seeking are focused on self-improvement, self-motivation, and self-worth. These findings for academic strategies support Tao and Hong's (2000) earlier research on how cultural values relate to academic excellence among Chinese students. In the current study, the participants described instances in which they felt obligations to achieve academically due in party to their Asian cultural values and family recognition.

Finally, the self-reliance strategy is also reflected in the Suggestions and Self-Reflection domains and related core ideas. The participants used the same thinking mode to give their peers suggestions and reflect their academic experiences. This finding adds to the literature in this area and may tell East Asian students that their help-seeking strategies start with depending on themselves when facing challenges and difficulties in a culturally different learning environment. Then this strategy would extend from self-reliance to dependence or integration.

\section{LIMITATIONS}

As with all studies, the current study had several limitations. First, some student participants (Korean and Japanese students) in our study used their second language (English) to answer our interview questions while some of them (Chinese and Taiwanese students) did in Mandarin. Therefore, they could have possibly held back information or given answers that did not completely express their thoughts, even though participants were given the opportunity to check the interview transcripts. Second, given social- 
desirability bias (Fisher, 1993) and Asian face-saving culture (Yang, 2002; Zane \& $\mathrm{Ku}, 2014)$, it is also possible that our participants provided perceived socially acceptable responses to questions rather than report their actual thoughts and feelings. Finally, our sample represented students from four of six East Asian countries and 53.8\% of participants were from China. These factors may have served as a limitation because our sample could not evenly cover all East Asian countries.

\section{IMPLICATIONS}

Findings from this study have several implications for college counselors, university administrators, and researchers. First, college counselors should be aware of the high learning motivation from the East Asian international students' perspective. Culturally skilled counselors can use these findings to improve their multicultural counseling competency while providing counseling services for students from East Asian countries. For example, nearly all participants reported that they experienced stress and even stigma related to English language proficiency. Counselors can use East Asian student clients' learning motivation to facilitate students' ability to make positive changes and improve their self-esteem during a counseling session. Second, given the findings on low psychological well-being related to academic adaptation, college counselors will be better prepared to help East Asian international students deal with such issues, including providing them with necessary assistance such as counseling and mentoring. University administrators should be aware of cultural and linguistic effects on students' academic adaptation and help mitigate acculturative stress (Berry, 1997) when they recruit students from East Asian countries. Finally, the findings of this study indicate that East Asian international students prefer to choose self-reliance strategies during their academic adaption. Self-reliance can be considered as a virtue; however, sometimes it could make people become reluctant to seek necessary help from others. College counselors and researchers may explore the reasons behind self-reliance strategies and their relationships with English language barriers (Li et al., 2016; Yan \& Berliner, 2013) and stigma (Vogel, Wester, \& Larson, 2007) among East Asian international students.

\section{FUTURE RESEARCH}

Future research exploring the academic adaptive experiences of East Asian international students using quantitative methods in collecting data would 
provide useful information for college counselors and university administrators who are interested in helping international students. For instance, participants in our study consists of students from four of six East Asian countries, nine undergrads, and more than $50 \%$ of participants from China; therefore, it is important to repeat the study with a more diverse and larger pool that evenly represents all East Asian countries. In addition, future studies could explore and compare the self-reliance strategies of East Asian international students who have different lengths of stay in the United States.

\section{REFERENCES}

Baba, Y., \& Hosoda, M. (2014). Home away home: Better understanding of the role of social support in predicting cross-cultural adjustment among international students. College Student Journal, 48, 1-15.

Berry, J. W. (1977). Immigration, acculturation, and adaptation. Applied Psychology: An International Review, 46, 5-34. doi: 10.111/ j.14640597.1977.tb01087.x

Berry, J. W. (2005). Acculturation: Living successfully in tow cultures. International Journal of Intercultural Relations, 29, 697-712. doi: 10.1016/j.ijintrel.2005.07.013

Biggs, J. B. (1996). Western misperceptions of the Confucian-heritage learning culture. In D. A. Watkins \& J. B. Biggs (Eds.), The Chinese learner: Cultural psychological and contextual influences (pp. 45-68). Hong Kong and Melbourne: Comparative Education Research Center and the Australian Council for Educational Research.

Bista, K. (2015). Asian international students' college experience: Relationship between quality of personal contact and gains in learning. Journal of International and Global Studies, 6, 38-54.

East Asia. (n.d.). Oxford Dictionary. Retrieved from http://www.oxforddictionaries. com/us/definition/american_english/east-asia?q=east+asia

Fisher, R. J. (1993). Social desirability bias and the validity of indirect questioning. Journal of Consumer Research, 20, 303-315.

Hamamura, T., \& Laird, P. G. (2014). The effect of perfectionism and acculturative stress on levels of depression experienced by East Asian international students. Journal of Multicultural Counseling and Development, 42, 205217. doi: 10.1002/j.2161-1912.2014.00055.x

Hill, C. E. (2010). Consensual qualitative research: A practical resource for investigating social science phenomena. Washington, DC: American Psychological Association.

Hill, C. E., Knox, S., Thompson, B. J., Williams, E. N., Hess, S. A., \& Ladany, N. (2005). Consensual qualitative research: An update. Journal of Counseling Psychology, 52, 196. doi: 10.1037/0022-0167.52.2.196 
Hill, C. E., Thompson, B. J., \& Williams, E. N. (1997). A guide to conducting consensual qualitative research. The Counseling Psychologist, 25, 517572. doi: 10.1177/0011000097254001

Holt, R. (2015). "Let the 'like' one in": Five portals to invite similarity into conversations about 'differences' in Asian Pacific communication. Journal of Asian Pacific Communication. 25, 78-96. doi: 10.1075/japc.25.1.1. 05hol

Institute of International Education. (2016). Open Doors data. Retrieved from http://www.iie.org/en/Research-and-Publications/Open-Doors/Data/ International-Students\#.VxlxyDArKUk

Johnson, P. (1988). English language proficiency and academic performance of undergraduate international students. TESOL Quarterly, 22, 186-168. doi: $10.2307 / 3587070$

Kondo-Brown, K. (2009). Heritage background, motivation, and reading ability of upper-level postsecondary students of Chinese, Japanese, and Korean. Reading in a Foreign Language, 21, 179-197.

Leder, G. C., \& Forgasz, H. J. (2004). Australian and international mature students: The daily challenges. Higher Education Research \& Development, 23, 183-198. doi: 10.1080/0729436042000206654

Leong, P. (2015). Coming to America: Assessing the patterns of acculturation, friendship formation, and the academic experiences of international students at a US college. Journal of International Students, 5, 459-474.

Li, G., Chen, W., \& Duanmu, J-L. (2010). Determinants of international students' academic performance: A comparison between Chinese and other international students. Journal of Studies in International Education, 14, 389-405. doi: 10. 1177/1028315309331490

Li, J., Liu, X., Wei, T., \& Lan, W. (2013). Acculturation, Internet use, and psychological well-being among Chinese international students. Journal of International Students, 3, 174-192.

Li, J., Marbley, A. F., Bradley, L., \& Lan, W. (2016). Attitudes toward seeking counseling services among Chinese international students: Acculturation, ethnic identity, and language proficiency. Journal of Multicultural Counseling and Development, 44, 65-76. doi: 10.1002/jmcd.12037

Li, J., Wang, Y., \& Xiao, F. (2014). Psychological wellbeing of East Asian international students: A systematic literature review. Journal of International Students, 4, 301-313.

Liao, K. Y., \& Wei, M. (2014). Academic stress and positive affect: Asian value and self-worth contingency as moderators among Chinese international students. Cultural Diversity and Ethnic Minority Psychology, 20, 107-115. doi: $10.1037 / \mathrm{a} 0043071$

Light, R. L., Xu, M., \& Mossop, J. (1987). English proficiency and academic performance of international students. TESOL Quarterly, 21, 251-261. doi: $10.2307 / 3586734$ 
Liu, J. (2001). Asian students' classroom communication patterns in U.S. university: An emic perspective. New York: Greenwood.

Mak, A. S., Bodycott, P., \& Ramburuth, P. (2015). Beyond host language proficiency: Copying resources predicting international students' satisfaction. Journal of Studies in International Education, 19, 460-475. doi: 10.1177/1028315315587109

Martirosyan, N. M., Hwang, E., \& Wanjohi, R. (2015). Impact of English proficiency on academic performance of international students. Journal of International Students, 5, 60-71.

McClure, J. W. (2003). The experiences of Chinese international postgraduates studying in Singapore (Doctoral dissertation). Retrieved from https://experts.griffith.edu.au/publication/nf6d46b3be22c087c43fde675998 $78 \mathrm{cb} 1$

Misra, R., Crist, M., \& Burant, C. (2003). Relationship among life stress, social support, academic stressors and reactions to stressors of international students in the United States. International Journal of Stress Management, 10, 137-157. doi: 10.1037/1072-5245.10.2.137

NAFSA: Association of International Educators. (2015). Welcoming foreign students to U.S. institutions is vital to American public policy. Retrieved from https://www.nafsa.org/_/File/_/2016_campaign_issuebrief.pdf

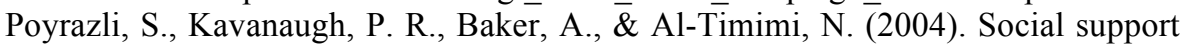 and demographic correlates of acculturative stress in international students. Journal of College Counseling, 7, 73-82. doi: 10.1002/j.2161-1882.2004. tb00261.x

Ritter, Z. S. (2015). Taboo or Tabula Rasa: Cross-racial/cultural dating preferences amongst Chinese, Japanese, and Korean international students in an American university. Journal of International Students, 5, 405-419.

Rosenthal, D. A., Russell, J., \& Thomson, G. D. (2008). The health and wellbeing of international students at an Australian university. Higher Education, 55, 51-67. doi: 10.1007/s10734-006-9037-1

Roy, S. R. (2013). Educating Chinese, Japanese, and Korean international students: Recommendations to American professors. Journal of International Students, 3, 10-16.

Samuelowicz, K. (1987). Learning problems of international students: Two sides of a story. Higher Education Research \& Development, 6, 121-134. doi: 10.1080/072943687006024

Spinks, J. A., \& Ho, D. Y. F. (1984). Chinese students at an English-language university: Stressors in the United States. Journal of College Student Development, 54, 62-84. doi: 10.1353/csd.2013.0010

Tao, V., \& Hong, Y. Y. (2000). A meaning system approach to Chinese students' achievement goals [Chinese]. Journal of Psychology in Chinese Societies, $1,13-38$. 
Vogel, D. L., Wester, S. R., \& Larson, L. M. (2007). Avoidance of counseling: Psychological factors that inhibit seeking help. Journal of Counseling \& Development, 85, 410-422. doi: 10.1002/j.1556-6678.2007.tb00609.x

Watkins, D. A. (1996). Hong Kong secondary school learners: A developmental perspective. In D. A. Watkins \& J. B. Biggs (Eds.), The Chinese learner: Cultural psychological and contextual influences. (pp. 107-120). Hong Kong and Melbourne: Comparative Education Research Center and the Australian Council for Educational Research.

Wong, J. (2004). Are the learning styles of Asian international students culturally or contextually based? International Education Journal, 4, 154-166.

Yan, K., \& Berliner, D. C. (2013). Chinese international students' personal and sociocultural stressors in the United States. Journal of College Student Development, 54, 62-84. doi: 10.1353/csd.2013.0010

Yang, S. (2002). 'Chaemyoun-saving (Face saving)' due to Koran job loss: Listening to men's voices. Journal of Comparative Family Studies, 33, 7395.

Yeh, C. J., \& Inose, M. (2003). International students' reported English fluency, social support satisfaction, and social connectedness as predictors of acculturative stress. Counseling Psychology Quarterly, 16, 15-28.

Yu, B., \& Downing, K. (2011). Determinants of international students' adaptation: Examining effects of integrative motivation, instrumental motivation and second language proficiency. Journal of Educational Studies, 38, 457-471. doi: $10.1080 / 03055698.2011 .643111$

Zane, N., \& Ku, H. (2014). Effects of ethnic match, gender match, acculturation, cultural identity, and face concern on self-disclosure in counseling for Asian Americans. Asian American Journal of Psychology, 5, 66-74. doi: $10.1037 / \mathrm{a} 0036078$

Zhou, Y., Frey, C., \& Bang, H. (2011). Understanding of international graduate students' academic adaptation to a U.S. graduate school. International Education, 41, 76-94.

JIAQI LI, PhD, LPC, NCC, is an Assistant Professor at the Department of Counseling, Educational Leadership, Educational and School Psychology, Wichita State University. His research interests include cross-cultural adaptation, career counseling, Internet addiction, and child and adolescent counseling as well as emotional disturbance, play therapy, and academic achievement in the school setting. Email: jiaqi.li@wichita.edu

YANLIN WANG, PhD, is a Visiting Assistant Professor of Chinese in the Department of Classical and Modern Languages and Literatures at Texas Tech University. She received her Doctor of Education in Instructional Technology at Texas Tech University. Her research focuses on technology 
assisted foreign language teaching, especially Chinese language as a foreign language teaching. Email: yanlin.wang@ttu.edu

XUN LIU, PhD, is a Postdoc Fellow in the Department of Foundations of Education in the School of Education at Virginia Commonwealth University. She received her PhD in Educational Psychology at Texas Tech University. Her research focuses on quantitative research methodology, marriage and family studies, educational motivation studies, and scale development and measurement. Email: xliu9@vcu.edu

YUSU XU, is a Senior Lecturer in School of Foreign Languages at Zhejiang Gongshang University. Email: xuyusu@126.com

TINGTING CUI is a Senior Lecturer in School of Foreign Language Education at Jilin University. Email: christinacui@126.com 